\title{
Knowledge Monitoring, Goal Orientations, Self-Efficacy, And Academic Performance: A Path Analysis
}

Ibrahim S. Al-Harthy, Sultan Qaboos University, Oman Christopher A. Was, Kent State University, USA

\begin{abstract}
The purpose of this study was to examine the relationship between knowledge monitoring and motivation as defined by self-efficacy and goal orientations. A path model was proposed to hypothesize the causal relations among predictors of the students' total score in the Educational Psychology course. The sample consisted of undergraduate students enrolled in two sections of the Educational Psychology course at a large Midwestern university. The data collection process took place during two semesters (Fall 2010 and Spring 2011). Subjects completed a knowledge monitoring assessment (KMA) and combined scale of self-efficacy and goal orientations online. Results of the study confirmed the positive correlations between knowledge monitoring, selfefficacy, mastery goals, and total exam score. The path analysis revealed that two predictors had significant direct effects on total score, knowledge monitoring and mastery goals. Self-efficacy had a significant direct effect on mastery goals. Although self-efficacy significantly correlated with total score, the parameter between self-efficacy and total score was not significant. Knowledge monitoring did not significantly correlate with self-efficacy and mastery goals. The path analysis revealed no significant exogenous parameters from or to performance goals. The current study provided some insights in understanding the relationship between knowledge monitoring and motivation as defined by self-efficacy and goal orientations. Recommendations and suggestions for future research were discussed.
\end{abstract}

Keywords: Knowledge Monitoring; Goal Orientations; Self-Efficacy; Academic Performance

\section{INTRODUCTION}

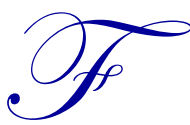

lavell (1979) described metacognition as learners' knowledge of their own cognition, defining it as "knowledge and cognition about cognitive phenomena" (p. 906). A large number of investigations have supported the importance of metacognition within educational contexts. Evidence supports the conclusion that students with good metacognition demonstrate higher academic performance when compared to students with poor metacognition (e.g., Bembenutty, 2007; Lan, 1996; Pintrich \& DeGroot, 1990; Vrugt \& Oort, 2008).

Despite decades of research on metacognition, more research is needed to understand the different components of metacognition and the relationship of metacognition to other variables within learning contexts. Perhaps a greater understanding can be found in the potential relationship between knowledge monitoring and motivational variables. Although the corpus of research in the area of metacognition has hypothesized a significant relationship between metacognition and motivation (e.g., Heils \& van Kraayenoord, 2003; Yunus \& Ali, 2008), only a limited amount of research has explored the potential existence of a significant relationship between components of metacognition and motivational variables, such as self-efficacy and goal orientations (Coutinho, 2008; Tobias, Galvin, \& Michna, 2002). Understanding these relationships may help educators to identify students in the classroom who are metacognitively aware but not highly motivated to succeed academically, or perhaps more important, the student who wants to learn but struggles with metacognition, and thus help the educator to select the 
best solutions for their students. Such solutions may include attempting to enhance students' motivation or promoting more effective learning strategies that may enhance students' metacognition.

The main focus of the present study was to examine the relationship between knowledge monitoring, selfefficacy, goal orientations, and academic performance. Knowledge monitoring as described by Tobias and Everson (2009) is the ability to monitor prior knowledge or what has been learned previously in a particular academic domain. It has been argued that knowledge monitoring is a fundamental or prerequisite metacognitive process (Tobias \& Everson, 2009, 1996). The rationale for this assumption is that students' effective control of their learning cannot occur in the absence of accurate knowledge monitoring. Tobias and Everson (2009) argued that knowledge monitoring is central to learning from instruction in school and in training settings in business, industry, and government. Tobias and Everson (2009) concluded that advanced metacognitive activities, such as evaluating learning, selecting appropriate learning strategies and planning for future learning activities, could not occur without accurate knowledge monitoring. Previous investigations indicated that the students' ability to accurately monitor their prior knowledge is highly related to reading achievement and general academic achievement (Everson, Smodlaka, \& Tobias, 1994; Tobias, Hartman, Everson, \& Gourgey, 1991) and to mathematics achievement (Campione, Brown, \& Connell, 1989). Nevertheless, to draw the conclusion that knowledge monitoring is an essential ability for human learning requires further research regarding the relationship between knowledge monitoring and motivation to determine and to fully understand its impact. One might inquire, "Why should this relationship be investigated?" The answer to this question comes from studies that demonstrate the importance of motivation as an essential variable in any learning setting that affect students' behaviors and eventually their academic performance (Meece, Anderman, \& Anderman, 2006; Moore, 2007; Verkuyten, Thijs, \& Canatan, 2001). Research has indicated that motivation initiates, directs, and maintains the activities controlling learning. However, Tobias and Everson (2009) argued that motivation can affect students' learning only by engaging the metacognitive processes controlling it. Put differently, highly motivated students who are willing to invest considerable effort to accomplish their academic goals are unlikely to be effective unless they also possess accurate knowledge monitoring skills. Our goal in the current investigation was to determine the validity of this assumption. Therefore, knowledge monitoring accuracy was measured and its relationships with the motivational components self-efficacy, goal orientations, and academic performance were examined.

Self-efficacy and goal orientations were among the variables investigated in the current study. One might question why self-efficacy and goal orientations, particularly, were used in the current research. To begin, there is a growing body of literature demonstrating that self-efficacy is an important variable that influences students' motivation and plays a critical role in students' performance (Al-Harthy, Was, \& Isaacson, 2010; Andrew, 1998; Bandura, 1993; Barkly, 2006; Paulsen \& Gentry, 1995; Schunk, 1981, 1989; Zimmerman, 2000). Academic selfefficacy refers to students' beliefs about their ability to perform academic tasks at designated levels (Schunk, 1991). Bandura (1977) defined perceived self-efficacy as personal judgments of one's capabilities to organize and execute actions to attain designated goals. Bandura (1993) argued that different motivational theories were built around three different forms of motivation: causal attributions (attribution theory), outcome expectancies (expectancy-value theory), and academic goals (achievement goal theory). Bandura also contended that beliefs of self-efficacy operate in all of these motivational forms. More specifically, students with high self-efficacy attribute their failures to a lack of effort, whereas those with low self-efficacy attribute their failures to a lack of ability (Bandura 1993; Collins, 1982). Bandura (1993) concluded that "casual attributions affect motivation, performance, and affective reactions mainly through beliefs of self-efficacy" (p. 128). Self-efficacy for learning involves assessing what will be required in the learning context and how well one can use knowledge to perform.

Self-efficacy affects behavioral functioning by influencing individuals' choices of academic activities. Previous research indicates that the higher one's perceived self-efficacy, the greater one's continued involvement in the activities and subsequent achievements will be (Schunk, 1981). A study conducted by Coutinho (2008) demonstrated that the influence of self-efficacy on academic performance is independent of students' metacognitive ability (Coutinho, 2008). Although knowledge monitoring is a key component of metacognition, we were unable to locate any studies that examined the relationship between self-efficacy and knowledge monitoring. Investigating this relationship not only increases our understanding about students' learning, but also helps scholars to evaluate cases in classroom settings in which students are highly motivated to learn but do not meet class performance requirements. 
Goal orientation is another motivational factor that has a significant impact on student learning outcomes. As described by Dowson and McInerney (2001), and based on achievement goal theory, goals are defined as "cognitive representations of the different purposes students may adopt for their learning in achievement situations" (p. 35). In the present study, goal orientation is considered an important component of motivation. Bandura (1993) argued that motivation involves cognitive comparison processes and these processes are produced based on the goals students set for their learning. The comparison processes differ as per different goals. He argued that by making self-satisfaction conditional on matching adopted goals, students set directions for their behaviors in order to accomplish their goals. Given this, it can be concluded that goal orientations affect students' motivation by providing standards from which self-satisfaction is drawn. In addition, research conducted by Elliot and Church (1997) has demonstrated that when achievement goals are taken into account, achievement motivation (desire to succeed) has no residual effect. Motives may "arouse or activate certain types of goals, but the goals then serve to guide and direct behavior and achievement" (Pintrich \& Maeher, 2001, p. 16, as cited in Bandura, 1993).

Most research on achievement goal orientation has addressed three types of goals (trichotomous framework): mastery, performance-approach, and performance-avoidance goals. In our study, goal orientation was operationalized using the trichotomous framework because of the large amount of research that proved the framework stability. Mastery goals focus on the development of competence and task mastery (Ames \& Archer, 1988; Was, 2006). Students who adopt mastery goals in certain achievement contexts believe that competence develops over time through practice and effort. They choose tasks that maximize opportunities for learning, invest considerable effort in tasks, use learning strategies that promote comprehension of course material, evaluate their own performance in terms of the progress they make, persist in the face of failure, view errors as a normal and useful part of the learning process, and subsequently use their errors to help improve performance (Elliot, 1999).

The second type of goal is performance-approach goals, which focus on the demonstration of competence relative to others. Students who adapt performance-approach goals for learning believe that competence is a stable characteristic (Dweck, 1986; Was, 2006). They choose tasks that maximize opportunities for demonstrating competence and avoid tasks that might make them look incompetent, invest the minimal effort needed to succeed, evaluate their own performance in terms of how they compare to others, view errors as a sign of failure and incompetence, give up easily when they fail and avoid tasks that have previously led to failure (Elliot, 1999; Nicholls, 1984; Somuncuoglo \& Yildirim, 1999). Of course, not all students set positive goals in the classroom; therefore, theorists have also identified a performance-avoidance goals orientation, which focuses on effort minimization to protect self-worth. For example, a student who is performance-avoidance oriented may produce less effort in certain tasks to avoid social judgment, which might reveal that s/he is less capable than her or his peers.

In addition, another goal that has been addressed in literature is work-avoidance where failure is avoided without hard work and achievement is viewed as completing the task with as little effort as possible (Brophy, 2005). Furthermore, Elliot (1999) discussed a 2 X 2 achievement goals framework. He argued that like performance goals, mastery goals can be separated into approach and avoidance orientations. In the 2 X 2 achievement goals framework, there are four independent goals: mastery-approach, mastery-avoidance, performance-approach, and performance-avoidance. However, Elliot conceded that empirical data regarding mastery-avoidance goals were not available at the time, and that predictions are somewhat difficult to generate because of the two conceptions of these goals, which seem to evoke a rather divergent set of processes. A second distinction in mastery orientation is that of task-referential versus past-referential orientation. Past-referent students use past performance as the measure of achievement, and as a scale by which to set new goals, whereas mastery task-referent students measure their competence according to whether they complete or fully understand the task at hand (Elliot, 1999).

Recently, a 3 X 2 model of achievement goal orientation was proposed (Elliot, Murayama \& Pekrun, 2011). In this model, goal orientation is divided into six goals based on the three standards (task, self, and other) used to define competence crossing with the two ways that competence may be valenced (approaching success and avoiding failure). These goals are: task-approach goal focused on the attainment of task-based competence, taskavoidance goal focused on the avoidance of task-based competence, self-approach goal focused on the attainment of self-based competence, self-avoidance goal focused on the avoidance of self-based competence, other approach goal focused on the attainment of other-based competence, and other avoidance goal focused on the avoidance of otherbased competence. Our study took place before the $3 \times 2$ model was introduced to the research literature and we 
encourage the future research to investigate this model and examine the relationships with academic achievement and other educational factors.

There is minimal extant research regarding the relationship between goal orientations and knowledge monitoring (however see Njoku, 2007; Stavrianopoulus, 2004, as cited in Tobias \& Everson, 2009). Tobias and Everson (2002) examined the relationship between knowledge monitoring, help seeking, and achievement goal orientations. A trichotomous framework of goal orientation was used. Subjects completed a goal questionnaire that developed by Pintrich and Maeher (2001). A knowledge monitoring assessment consisting of 42 words was administered by computer. On the first 21 words, participants were asked to estimate their knowledge of each word and then were instructed to complete a multiple choice test on the words. During the first 21 words and after completing the test, subjects were also given the opportunity to request help on words either by receiving a definition or an example of the word used in a sentence. The procedures were identical during the second set of words, except that feedback about subjects' answers on the test was provided before using the help request option. The results indicated that goal orientations had no effect on monitoring accuracy or on help seeking.

An experimental design was used in a doctoral dissertation conducted by Stavrianopoulus (2004, as cited in Tobias \& Everson, 2009) to investigate the effects of motivational goals on metacognitive knowledge monitoring and help seeking. Participants received different instructions to induce a trichotomous framework of goal orientations. Participants also completed a KMA consisting of 40 authentic vocabulary words and five nonsense words where they were able to request help with only ten words. Results indicated that goal orientations did not affect students' knowledge monitoring accuracy.

A doctoral dissertation conducted by Njoku (2007, as cited in Tobias \& Everson, 2009). Njoku compared high school students from Nigeria to American students in knowledge monitoring ability. Participants completed a KMA consisting of 24 mathematics word problems and a motivational goals questionnaire developed by Pintrich and Maehr (2001). The results showed that American students were more accurate knowledge monitors than Nigerian students. More important, the results demonstrated that mastery oriented students were more accurate at knowledge monitoring.

All reported research provided support for the predictions dealing with the positive relationship between knowledge monitoring and academic achievement; however, the previous research has failed to confirm expectations dealing with achievement goal motivation theory. In addition, no research was found that investigated the relationship between self-efficacy and knowledge monitoring. The goal of the current study was to develop a causal model for explaining students' academic achievement. More specifically, this study investigated the causal effects among the following variables: knowledge monitoring accuracy, self-efficacy, goal orientations, and students' performance. The hope was that the present study would contribute to the existing body of research on knowledge monitoring and clarify its relationship with academic performance by including self-efficacy and goal orientations in the model.

A strong positive relationship was expected between knowledge monitoring ability and students' selfefficacy. The rationale behind this hypothesis was that previous results included a high correlation between selfefficacy and metacognitive self-regulation skills (e.g., Al-Harthy et al., 2010). In addition, based on Bandura's definition of self-efficacy, students with high self-efficacy usually engage in cognitive activities, such as personal judgments of their capabilities, assessment of what will be required and how one performs in certain learning contexts. It has been argued that such cognitive activities could not occur without accurate knowledge monitoring (Tobias \& Everson, 2002). Given that the ability to differentiate between what is known (learned) and unknown (unlearned) is an important ingredient for success in all academic settings, the proposed path model (Figure 1) represented the hypothesis that knowledge monitoring would predict academic self-efficacy and would have a strong effect on students' final scores. Furthermore, because self-efficacy involves the use of the cognitive activities discussed above and has been demonstrated to be a strong predictor of students' performance, the proposed path model (Figure 1) hypothesized that academic self-efficacy would mediate the relationship between knowledge monitoring and students' performance. 
The research conducted investigating the relationship between goal orientations and knowledge monitoring has not yet settled the debate regarding various causal effects in the model. The inconsistency in the results regarding the relationship between knowledge monitoring and goals implies more research is needed to study the effects of knowledge monitoring on students' performance by adding goal orientations to the model. Utilizing logic and theory, the path model proposed is shown in Figure 1.

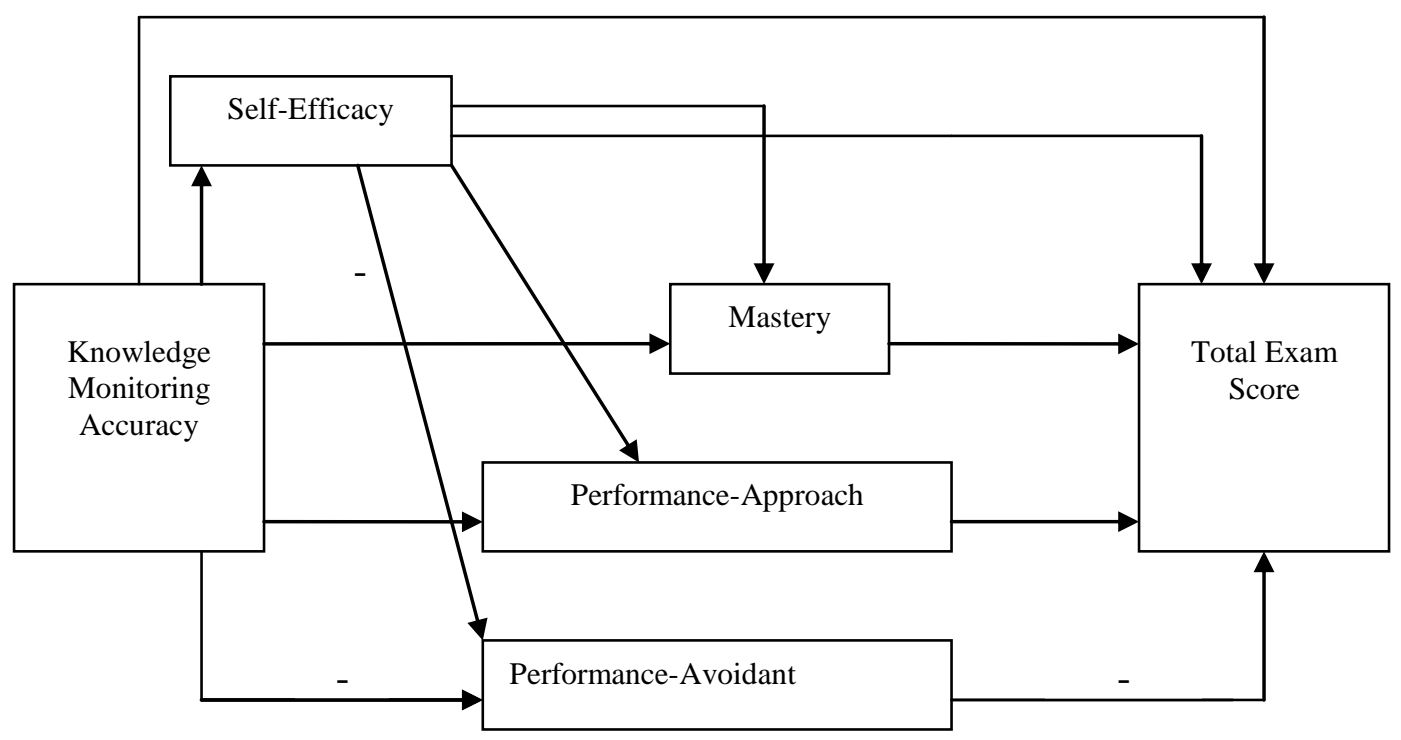

* Minus signs (-) represent a path hypothesized to be negative.

Figure 1: Hypothesized Path Model

\section{METHOD}

\section{Sample}

The participants were 125 undergraduate students enrolled in two sections of the Educational Psychology course at Kent State University. Seventy four percent of the participants were female and all were of sophomore status. The data collection process took place during two semesters (Fall 2010 and the Spring 2011). One instructor taught the Educational Psychology course during both semesters.

\section{Instruments}

\section{Achievement Goal Orientation}

The achievement goal questionnaire was adopted from Patterns of Adaptive Learning Scales (PALS: Midgley et al., 2000). The questionnaire comprised 14 items, five items each for mastery $(\alpha=.85)$ and performance-approach $(\alpha=.89)$ goal orientations and four items $(\alpha=.74)$ measure performance-avoidance goals orientation. Items in the achievement goal questionnaire have been adapted to measure domain-specific goals in the Educational Psychology courses. For example, the first item on the Mastery Goals Orientation Scale, "It's important to me that I learn a lot of new concepts this year," was rephrased for the sample of the proposed study as, "It is important to me that I learn a lot of new concepts in this class."

\section{Self-Efficacy}

A subscale that measures academic self-efficacy was adopted from PALS (Midgley et al., 2000; see Appendix B). The subscale consisted of five items $(\alpha=.78)$ that measure students' perceptions of their competence 
to do their class work. Because the study aimed to measure domain-specific efficacy in the Educational Psychology course, one item has been rephrased to measure domain-specific efficacy. This item, "I'm certain I can master the skills taught in class this year," was rephrased as, "I'm certain I can master the skills taught in class." The other four items remained the same.

\section{Knowledge Monitoring Assessment (KMA)}

A version of the knowledge monitoring assessment (KMA) (Isaacson \& Was, 2010) was adapted to measure knowledge monitoring accuracy. This measure was modeled after a measure developed by Tobias and Everson (1995). The KMA consisted of 50 English vocabulary words. Thirty-three of the vocabulary words were derived from the text used for the Educational Psychology course and 17 were general vocabulary words from the English language.

\section{Academic Performance}

Academic performance was measured by students' total exam score in the Educational Psychology course. Students' grades were calculated as the sum of 12 exams worth 100 points each. The students were administered one exam per week for the period of 12 weeks.

\section{Procedures}

The data collection for the current study took place during two academic semesters (Fall 2010 \& Spring 2011). During the first week of each semester, participants were given written information regarding the purpose of the study. The information included that they are participating in a study concentrating on students' estimates of what they know, how they perform and how this is related to some motivational variables. Participants were instructed to complete the KMA online during the first two weeks of the semester in their Educational Psychology course. During the administration of the KMA, participants were presented with 50 English vocabulary words one at a time. They were asked to estimate whether they could or could not define the word by checking "know" or "don't know". The second part of the KMA consisted of a multiple choice vocabulary test, which was administered to the participants after they finished the first part. During the second part of the KMA, the same 50 vocabulary words as in the first part were presented. Participants were introduced with the vocabulary item and five possible definitions for each word and were instructed to check the word that best defines the word on the screen.

The Achievement Goal Orientations scale (14 items) and Self-Efficacy scale (5 items) were combined in one questionnaire, which was completed online. Participants were instructed to indicate the extent to which they believe each item to be true on a 1 (strongly disagree) to 5 (strongly agree) scale.

The total exam score for the course was composed of students' scores on 12 exams worth 100 points each. The exams were administered one per week. Students' scores on the 12 exams were summed to calculate students' total score in the Educational Psychology course. All data were entered into the Statistical Package for the Social Sciences (SPSS) for analysis.

\section{RESULTS}

Knowledge monitoring accuracy was measured by obtaining a gamma coefficient $(\gamma)$. The formula below shows how the gamma coefficient $(\gamma)$ was calculated. Table 1 presents the four possible outcomes that were used to compute a gamma coefficient $(\gamma)$. Two scores (hits and correct rejections) represent accurate knowledge monitors, while the other two scores (misses and false alarms) represent inaccurate knowledge monitors. To compute monitoring accuracy, each response was assigned to one of the four categories (possible outcomes). Based on the frequency of responses in each of the four categories, a gamma coefficient $(\gamma)$ was calculated for each participant.

$\operatorname{Gamma}$ coefficient $(\gamma)=\frac{\text { (hit) }(\text { correct rejection })-(\text { miss })(\text { false alarm })}{\text { (hit) }(\text { correct rejection })+(\text { miss })(\text { false alarm })}$ 
Table 1: Knowledge Monitoring Possible Scores

\begin{tabular}{ccc}
\hline & Know & Don't Know \\
\hline Correct & Hit & False Alarm \\
Incorrect & Miss & Correct Rejection \\
\hline
\end{tabular}

Table 2 provides the descriptive statistics for the measured variables. Principle component analysis (PCA) was conducted using a varimax rotation on the 19 items of self-efficacy and goal orientations to determine their underlying dimensions. The PCA retained three components. After rotation, together the three components accounted for $57.82 \%$ of the total variance. The first component accounted for $26.06 \%$ of variance, the second component for $22.4 \%$, and the third component for $9.35 \%$. Having found that performance-approach goals items and performance-avoidant goals items loaded on one factor, the dichotomous model (mastery goals and performance goals) of achievement goals was the best model to represent the data. The PCA revealed a final model of three factors, which were self-efficacy, mastery goals, and performance goals. Three variables were developed by summing item responses in each dimension of the three factor model of self-efficacy and goal orientations.

Table 2: Mean and Standard Deviation of Observed Variables

\begin{tabular}{|c|c|c|c|}
\hline Variables & $\mathbf{M}$ & SD & $\mathbf{N}$ \\
\hline Total Score & 1064 & 81 & 125 \\
\hline Knowledge Monitoring & .55 & .31 & 125 \\
\hline Self-Efficacy & 21 & 2.5 & 125 \\
\hline Mastery Goal & 23 & 1.7 & 125 \\
\hline Performance Goal & 26 & 5.9 & 125 \\
\hline
\end{tabular}

The level of internal consistency was examined using Cronbach's alpha after the three components were retained. Table 3 presents the coefficient alpha $(\alpha)$ for the three factors and shows that the reliability data still suggests high consistency in students' responses to the items.

Table 3: Reliabilities among the Three Factors

\begin{tabular}{lcc}
\hline \multicolumn{1}{c}{ Factor } & Items & Coefficient Alpha (a) \\
\hline Performance Goal & $1,2,4,6,8,10,12,13,17$ & .883 \\
Mastery Goal & $3,5,9,15,19$ & .753 \\
Self-Efficacy & $7,11,14,16,18$ & .859 \\
\hline
\end{tabular}

Table 4 presents the correlations between all variables in the study. Relations between variables in the conceptual model were first examined with Pearson product-moment. The correlation analysis was completed to examine the relational patterns of the variables of interest. Knowledge monitoring, self-efficacy, and mastery goals factors significantly correlated with total score $(r=.289, r=.188, r=.233$, respectively). The performance goals factor did not significantly correlate with the total score. In addition, the self-efficacy factor significantly correlated with mastery goals factor $(\mathrm{r}=.453)$. Knowledge monitoring did not significantly correlate with motivational variables in this study.

Table 4: Correlations of Observed Variables

\begin{tabular}{|c|c|c|c|c|c|}
\hline Variables & 1. & 2. & 3. & 4. & 5. \\
\hline 1. Total Score & & & & & \\
\hline 2. K-M & $.289 * *$ & & & & \\
\hline 3. Self-Efficacy & $.188 *$ & .020 & & & \\
\hline 4. Mastery & $.233 * *$ & -.101 & $.453 * *$ & & \\
\hline 5. Performance & .087 & -.024 & .078 & .022 & \\
\hline
\end{tabular}

Note: ${ }^{1} \mathrm{~K}-\mathrm{M}=$ knowledge monitoring. ${ }^{2} * *=p<.01 .{ }^{3} *=p<.05$.

Standard multiple regression was conducted to determine how the independent variables (knowledge monitoring, self-efficacy factor, mastery goals factor, and performance goals factor) predict students' total score in the Educational Psychology course. Results from Table 5 indicated the $t$ statistics for the regression coefficient of knowledge monitoring and mastery goals factors were statistically significant. Hierarchical regression model was used to determine the unique contribution of the significant predictors. The results also indicated that after controlling for self-efficacy factor, mastery goals factor, and performance goals factor, the unique contribution of 
knowledge monitoring for the prediction of total score was statistically significant, $F(1,125)=14.252, p=.000$. Moreover, the results showed that after controlling for knowledge monitoring, self-efficacy factor, and performance goals factor, mastery goals factor explained a unique proportion of variability on total score, $F(1,125)=6.804, p=$ .010 . In contrast, the $t$ statistics for the regression coefficients of self-efficacy and performance goals factors were not statistically significant. Thus, there was no unique contribution of either of these two factors for predicting the total score.

Table 5: Summary of Multiple Regression Analysis for Variables Predicting Total Score

\begin{tabular}{|c|c|c|c|c|c|c|}
\hline & $R^{2}$ & $\boldsymbol{B}$ & $S E B$ & $B$ & $T$ & $P$ \\
\hline 1 & .083 & 79.157 & 20.973 & .310 & 3.775 & .000 \\
\hline 2 & .035 & 2.010 & 2.889 & .064 & .696 & .488 \\
\hline 3 & .054 & 11.349 & 4.351 & .239 & 2.609 & .010 \\
\hline 4 & .008 & 1.296 & 1.119 & .095 & 1.158 & .249 \\
\hline 5 & & 677.033 & 98.724 & & 6.858 & .000 \\
\hline
\end{tabular}

Note: 1 = knowledge monitoring; $2=$ self-efficacy; $3=$ mastery goal; $4=$ performance goal; and constant $=5 . N=125$

Path analysis was conducted using Amos 5 software (Arbuckle, 2003) employing maximum likelihood path analysis (Chou \& Bentler, 1995). The estimated standardized path coefficients are presented in Figure 2. As expected, the knowledge monitoring and mastery goals factors significantly correlated with total $\mathrm{score}(\mathrm{r}=.289, \mathrm{r}=$ .233 , respectively). Unexpectedly, self-efficacy and performance goals factors did not significantly correlate with the total score. However, the self-efficacy factor significantly correlated with mastery goals factor $(r=.453)$. For ease of understanding, Figure 3 presents the path model with only the statistically significant parameters. Table 6 presents the direct, indirect, and total effects of all predictor variables on total score.

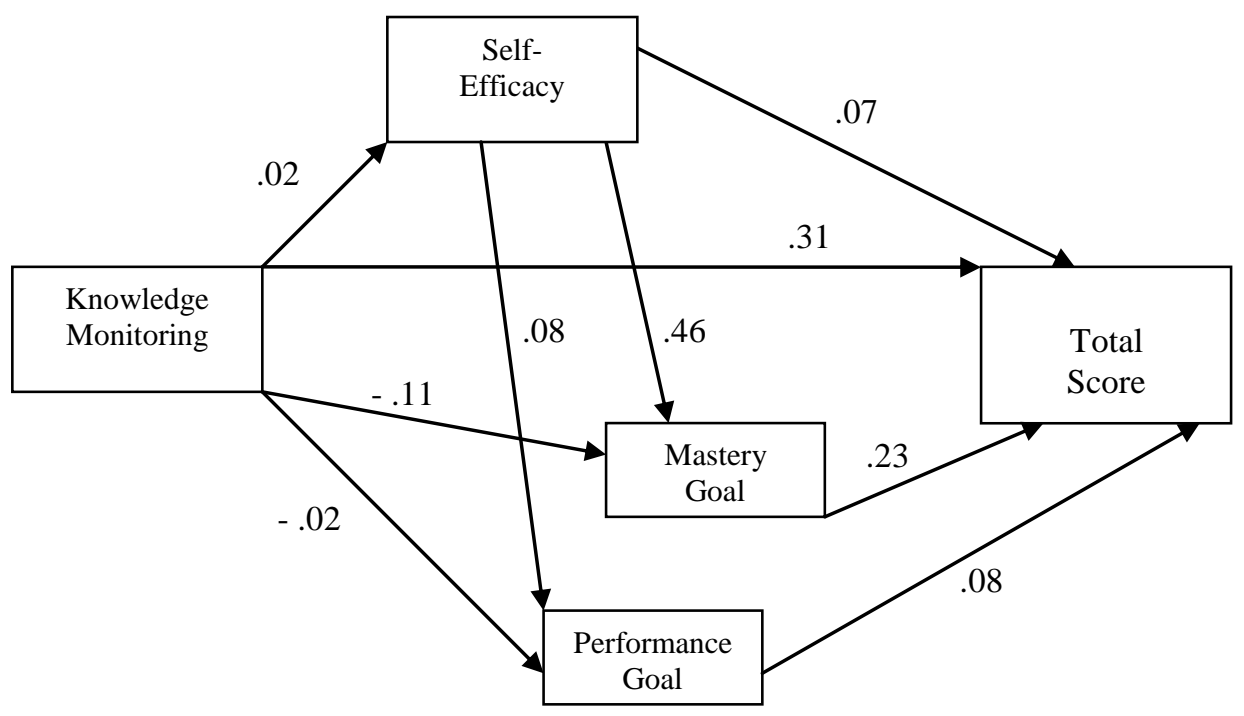

Figure 2: Path Model Tested with Standardized Path Coefficients

Table 6: Standardized Effects of Predictor Variables on Total Score

\begin{tabular}{lccc}
\hline \multicolumn{1}{c}{ Variable } & Direct Effects & Indirect Effects & Total Effects \\
\hline Knowledge Monitoring & .308 & -.024 & .283 \\
Self-Efficacy & .071 & .112 & .183 \\
Mastery Goal & .231 & .000 & .231 \\
Performance Goal & .086 & .000 & .086 \\
\hline
\end{tabular}




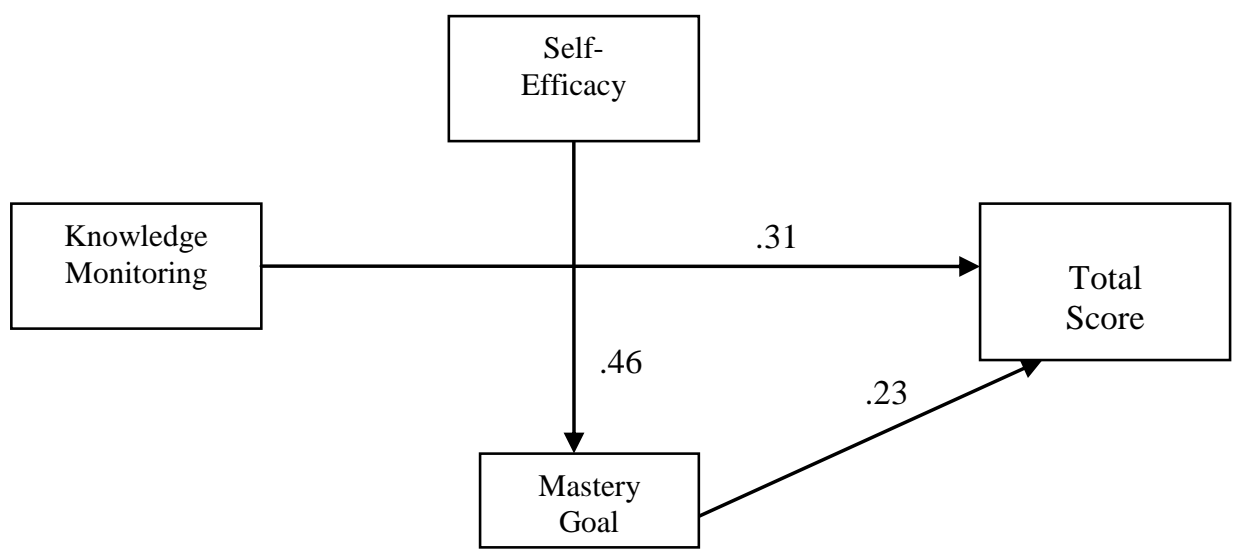

Figure 3: Path Model with Significant Path Coefficients

Two predictors had significant direct effects on total score, knowledge monitoring $(\beta=.308)$ and mastery goals factor $(\beta=.231)$. Self-efficacy factor had a significant direct effect on mastery goals factor $(\beta=.456)$. Although the zero order correlation between self-efficacy and total score was significant, the parameter between self-efficacy factor and total score was not significant $(\beta=.071)$. The path analysis revealed no significant exogenous parameters from or to performance goals factor.

\section{DISCUSSION}

The aim of the present study was to investigate the relationship between knowledge monitoring, selfefficacy, and achievement goal orientations. The study also investigated the relationship between these predictors and academic performance as reflected in examination grades. In addition, the study used the relationship between all measured variables to examine the proposed path model (Figure 1).

One primary objective of this study was to investigate whether students' exam scores in the educational psychology course could be predicted by individual differences in knowledge monitoring, self-efficacy, and achievement goal orientations. The results of this study showed a positive relationship between knowledge monitoring and total score. That is, students who are more accurate at knowledge monitoring performed significantly better as operationalized by the course total score. This finding parallels those of previous studies exploring students' monitoring accuracy (Campione et al., 1989; Everson et al., 1994; Hartwig et al., 2011; Tobias et al., 1991). Furthermore, as discussed in the introduction, investigation of this relationship and including motivational predictors of the academic achievement into the model will have important implications for education and for theory of self-efficacy and goal orientations.

As predicted, the direct and indirect effects of knowledge monitoring demonstrated a relationship to academic achievement. Regression analysis demonstrated that knowledge monitoring accounted for the most variance $(8 \%)$ in the total score. This effect size is noteworthy when one considers the different predictors that contribute to students' exam performance. Students' performance in the Educational Psychology course was significantly shaped by students' knowledge monitoring accuracy. One interpretation of this relationship is that the ability to differentiate between the learned and unlearned materials is an essential ability in the learning process. Tobias and Everson $(2009,1996)$ argued that knowledge monitoring is a prerequisite metacognitive process and the effective control of a student's learning cannot occur without accurate knowledge monitoring. In addition, an effective control of someone's learning requires some activities, such as evaluating learning and selecting appropriate learning strategies (Al-Harthy et al., 2010; Bembenutty, 2007; Vrugt \& Oort, 2008). 
Although the current study provided evidence for a positive link between knowledge monitoring and students' performance, knowledge monitoring did not significantly correlate with motivational predictors as defined by self-efficacy and goal orientations. The study hypothesized that self-efficacy and goal orientations would mediate the relationship between knowledge monitoring and total score. The relationship between self-efficacy, goal orientations and knowledge monitoring is largely unexplored. Goal orientations have been investigated as a predictor of students' achievement, but there is some support for its role as a mediator of knowledge monitoring. For example, research on knowledge monitoring (see Tobias \& Everson, 2009, for a review) has demonstrated that performance-avoidant goals partially mediated the relationship between knowledge monitoring and exam performance.

Self-efficacy and mastery goals involve the use of cognitive strategies, such as personal judgments of capabilities, assessment of what is required (Bandura, 1993), and using learning strategies that promote comprehension (Al-Harthy et al., 2010; Elliot, 1999). That being demonstrated, one would undoubtedly obtain a more-complete view of how high self-efficacy and mastery oriented students use these cognitive activities to control learning by engaging knowledge monitoring in the process of learning. For example, imagine two students studying the Arabic language. Both students are good knowledge monitors. One student studies Arabic because s/he plans to visit countries in which only Arabic is spoken and she believes that it is beneficial to speak the same language. In contrast, the second student does not like learning another language, but has to take the class to fulfill a requirement. In this example, high efficacy beliefs and mastery orientation have provided a valuable advantage to the first student, regardless of knowledge monitoring ability. It has been demonstrated that the first student, in this case, because of her/his efficacy beliefs and mastery orientations, would use cognitive strategies to help achieve the goal (Al-Harthy et al., 2010; Bandura, 1993; Elliot, 1999), which the researchers assumed that would require using knowledge monitoring. The authors assert that the current study provides some insights in understanding the relationship between knowledge monitoring and motivational variables and highlights the promise of exploring these relationships in future research.

Admittedly, the focus of measuring motivational variables at the beginning of the course semester may weaken the design of the current study. The motivational effects are not derived from the goals and self-efficacy themselves, but rather from the fact that students evaluate themselves as part of their responses to their own behaviors. It is important to acknowledge that patterns of goals may change across time: that is, as the students move into different learning situations that reflect the nature of the class, their academic goals may reflect to some degree the actual goals for that particular class. If so, students who initially had relatively low or high efficacy beliefs and adapted a certain goal orientation at the beginning of the course semester may have changed later on throughout the semester. Thus, one avenue for future research pertains to a potential limitation of this study: given that motivational variables were measured at the beginning of the semester, it was unclear whether these motivational variables were pre-existing variables students brought to the class or were adapted for the Educational Psychology class. Certainly, a first step for progress is merely demonstrating motivational measures at the beginning and at the end of the semester.

As predicted, the zero order correlation between self-efficacy, mastery goal orientation, and students' total score were significant. These results support predictions from self-efficacy and goal orientations theories. Students with high precepts of self-efficacy consequently persist longer, seek moderately challenging learning tasks, view failures as learning opportunities, and achieve more academic success (Al-Harthy et al., 2010; Bandura, 1986; Deemer, 2004). The social cognition model of motivation (Bandura, 1997) emphasized the role of perceptions of efficacy in determining individuals' striving for achievement. Bandura proposed that self-efficacy beliefs are the major determinant of goal setting, activity choice, willingness to expand effort, and persistence. Students form beliefs about what they can do, and then guide their learning accordingly. Also, they are more likely to anticipate outcomes of prospective actions. However, the results of the present study differed from those of previous research in terms of unique contribution that self-efficacy has on students' performance. In this study, the path model analysis revealed that the parameter between self-efficacy and total score was not a significant parameter in the model. The absence of a significant direct effect of self-efficacy factor on total score in the final model was most likely due to the distribution of shared variance with mastery goals factor. 
Bandura (1993) argued that one way that self-efficacy contributes to students' motivation is through goals. More specifically, self-efficacy beliefs determine the goals students set for themselves. The empirical support for this argument comes from a study conducted by Al-Harthy et al. (2010), where determination of goals depended on students' efficacy beliefs. Students with high self-efficacy adopted mastery goals for their learning, whereas those with low self-efficacy adapted performance-avoidant goals. The interpretation that self-efficacy affects students' total score by influencing the goals students adopt for their learning seems plausible and corresponds with previous research findings (e.g., Al-Harthy et al., 2010). The findings of the present study support the movement toward encouraging instructors to promote mastery goals in their teaching.

As hypothesized, the correlation between self-efficacy and mastery goals factors is a strong positive parameter in the model. The results of the current study showed that students with high self-efficacy were mastery oriented and had high academic achievement. This finding is consistent with the findings from previous research studies investigating relationships between self-efficacy and mastery goal orientation (Al-Harthy et al., 2010; Anderman \& Young, 1994; Meece et al., 1988; Middlleton, Kaplan, \& Midgley, 1998; Middleton \& Midgley, 1997; Midgley \& Urdan, 1995; Roeser, Midgley, \& Urdan, 1996; Skaalvik, 1997; Turner, Thorpe, \& Meyer, 1998; Wolters, Yu, \& Pintrich, 1996). The interpretation of this result is that students with high self-efficacy beliefs have high confidence in their ability to successfully perform certain tasks and set mastery goals and were more likely to see the educational psychology experience as a challenge rather than a threat. According to the social cognitive theory, students with high self-efficacy tend to persist in the face of difficulty, seek moderately challenging learning tasks, and view failures as learning opportunities (Bandura, 1986). All these aspects are theoretically consistent with the mastery goal orientation characteristics. Students set personal expectations for their learning in relation to their academic self-efficacy. Al-Harthy et al. (2010) argued that these expectations directly and indirectly affect students' goals by directing students to pursue specific goal orientation.

Another predicted parameter in the model was between mastery goals factor and total score. The interpretation of this result is that the mastery goals orient students toward a learning approach characterized by satisfaction upon mastery or completion of a task, with greater levels of efficacy, task value, metacognitive selfregulation (Al-Harthy et al., 2010), and greater use of cognitive and metacognitive strategies (Pintrich, 2000). In addition, mastery oriented students invest considerable efforts in tasks and use learning strategies that promote comprehension of course material. Most important, mastery oriented students perform self-learning evaluation and persist in the face of failure (Elliot, 1999).

Surprisingly, the results of path analysis (Figure 3) revealed no significant exogenous parameters to or from performance goals factor in the model. This finding is in line with and can be explained through a limited amount of research. Literature regarding goal orientations describes performance oriented students as displaying ability or looking good when compared to their classmates (Elliot, 1999; Nicholls, 1984; Somuncuoglo \& Yildirim, 1999). In contrast, when students are allowed to describe their goals using their own words, they rarely mention performance goals. They may aspire to pass a class or get a higher grade, but they seldom talked about friends (Urdan, 2001; Urdan, Kneisel, \& Mason, 1999). Brophy (2005) made another argument about self-reports measures of performance goals in the academic context. Brophy argued against the causal link between performance goals adoption and subsequent performance because of the effects that students' history of past achievement has on students when completing performance goals measure. These effects are perhaps reflected in the relationship between performance goals measure and measure of students' achievement. This argument adds more support to the suggestion made earlier in this discussion in that future research should consider applying goal orientations measures at different times during the academic semester in which the researcher conducting research.

In addition, social desirability is defined as students' tendency to present themselves in a favorable light and found to be a source of method bias in self-report questionnaire research. Jan and Hall (2005) demonstrated that social desirability affects goal orientations measure. They examined the social desirability effects on goals measures and found positive loadings for performance-approach goals on the social desirability construct. Another issue concerning the performance goals is when students define a specific adopted goal but eventually judge success relative to criteria that does not match the goals. For example, a student may set a goal of demonstrating competence but use personal improvement as a measure toward the goal. It seems reasonable to conclude that, under natural classroom conditions, performance goals are a low-incidence phenomenon; however, more research 
may need to be conducted to further examine the performance goals and its relationship with different classroom practices, such as teaching methods and assessment practices.

\section{CONCLUSION}

Despite decades of research on metacognition and motivation, few empirical research attempts have been made to link components of metacognition to motivation defined in self-efficacy and goal orientations. This study not only attempted to create this link by investigating the possible relationship between knowledge monitoring, selfefficacy and goal orientations, but also to explore how this relationship might add to our understanding of the variability in students' achievement. Based on the findings of this study, a number of recommendations for future research are suggested.

First, the results of this study support the conclusion about the robust positive relationship between knowledge monitoring and students' performance. Therefore, the nature of this predictor in classroom settings needs to be considered in future research. For instance, future research might focus on investigating different classroom practices that might assist students become accurate knowledge monitors. We should move on to concentrate on the practical and useful employment of knowledge monitoring to enhance teaching and facilitate students' learning.

Second, the current study did not provide evidence for the positive link between knowledge monitoring and motivation (as defined by self-efficacy and goal orientations.) However, the argument was that despite self-efficacy and goal orientations theories differ from metacognition construct in their conceptualization and measurement, they nevertheless involve the use of cognitive activities. The research discussed above demonstrated that self-efficacy and goal orientations involve cognitive activities, such as forming expectations and evaluating the learning process. This study continued the argument by testing the assumption that because of these cognitive activities, knowledge monitoring should in some way correlate to motivational variables. It might be a systematic bias that has affected the existence of this relationship. More specifically, the measurement of self-efficacy and goal orientations in this study took place at the beginning of the Educational Psychology course. The underlying dimensions of goal orientations may not be the same after students spend more time in the course and become more familiar with the course nature. Put differently, what subjects report regarding their goal orientations may not be the same as the perceptions and beliefs they have at the time they are actually engaging in different tasks. Thus, future research may need to examine the students' goal orientations at different times or stages of the semester. Greater accuracy might have been obtained if students were given the opportunity to express their goals and efficacy beliefs at different times in the semester; therefore, classroom observations and interviews could be critical in understanding what efficacy beliefs and goals students adopt for their learning.

Moreover, the present findings are consistent with goal orientations literature in that mastery goal orientation is a positive predictor of the students' achievement as defined by total score. The future research should move on to investigate which aspects of the classrooms practices may have effects on students goal orientations. Future research may need to independently consider each aspect of learning environment, such as class activities, and how could affect students goals.

A surprising finding of the current study was the absence of the performance goals factor from the path model. One possible explanation discussed above is the limitation of self-report measure used in this study. Another possible explanation might be that performance goals are not good goals to adapt for this particular class. This could be because of the teaching and assessment practices used in this class. Thus, fertile ground for research might improve the design of the current study by sampling additional classrooms, domains, and students.

In short, the present study is important because it started the argument, in view than has been the case to date, about the potential relationship between knowledge monitoring, self-efficacy, and goal orientations. Future research should address the ways in which these predictors interact with each other to influence students' academic performance and achievement. This study, for example, suggests that there is a need for an examination of how different components of metacognition, such as knowledge monitoring correlates with motivational variables, specifically, self-efficacy and goal orientations. Clearly, this relationship is more complex than initially anticipated, 
and a full understanding of this important relationship awaits experimental and field research attending to various features of classroom achievement situations. For instance, a future experimental study might assign subjects who are accurate and inaccurate knowledge monitors to different groups and manipulate self-efficacy and each of goal orientations each group. Using such an experimental design would explain more of this complex relationship and would detect any mediation that might exist.

\section{AUTHOR INFORMATION}

Ibrahim S. Al-Harthy is an Assistant Professor of Educational Psychology at Psychology Department. My bachelor's degree was in Education received from Oman. My master and PhD were on Educational Psychology received from Kent State University, USA. My research interest is learning, memory and cognition. I have different work experiences, among them was Cleveland Clinic for two years. I am looking forward for more collaboration on research. E-mail: ibrahimh@squ.edu.om (Corresponding author)

Christopher A. Was, is an Associate Professor of Educational Psychology at Kent State University. After receiving his Bachelor's degree in Psychology and Master of Science degree in Education awarded by Indiana University, he received his Ph.D. from the University of Utah in Educational Psychology, with an emphasis in learning, memory and cognition. Dr Was's research interests are in the areas of models of memory and complex cognitive processes, as well as metacognition. More recently his research has focused on implicit learning processes and their relationship to intelligence.

\section{REFERENCES}

1. Al-Harthy, I., Was, C., \& Isaacson, R. (2010). Goals, efficacy and metacognitive self-regulation: a path analysis. International Journal of Education, 2, 1-20.

2. Ames, C., \& Archer, J. (1988). Achievement goals in the classroom. Students' learning strategies and motivation process. Journal of Educational Psychology, 80, 260-267.

3. Anderman, E. M., \& Young, A. J. (1994). Motivation and strategy use in science: Individual differences and classroom effects. Journal of Research in Science Teaching, 31, 811-831.

4. Andrew, S. (1998). Self-efficacy as a predictor of academic performance in science. Journal of Advanced Nursing, 27, 596-603.

5. Bandura, A. (1977). Self-efficacy: Toward a unifying theory of behavioral change. Psychological Review, 84, 191-215.

6. Bandura, A. (1986). Social foundations of thought and action: A social cognition theory. Englewood Cliffs, NJ: Prentice-Hall.

7. Bandura, A. (1993). Perceived self-efficacy in cognitive development and functioning. Educational Psychologist, 28, 117-148.

8. Bandura, A. (1997). Self-efficacy: The exercise of control. New York: W. H. Freeman. Barkley, J. M. (2006). Reading education: Is self-efficacy important? Reading Improvement, 43, 194-210.

9. Bembenutty, H. (2007, April). Self-regulation of learning and academic delay of gratification among Korean college students. Paper presented at the Annual Meeting of the American Educational Research Association, Chicago, IL.

10. Brophy, J. (2005). Goal theorists should move on from performance goals. Educational Psychologist, 40(3), 167-176.

11. Campione, J., Brown, A., \& Connell, M. (1989). Metacognition: on the importance of understanding what you are doing. In R. Charles \& E. Silver (Eds.), The teaching and assessing of mathematical problem solving (pp. 93-114). Reston VA: National Council of Teachers of Mathematics.

12. Collins, J. L. (1982, March). Self-efficacy and ability in achievement behavior. Paper presented at the annual meeting of the American Educational Research Association, New York.

13. Coutinho, S. (2008). Self-Efficacy, metacognition, and Performance. North American Journal of Psychology, 10(1), 165-172.

14. Deemer, S. A. (2004). Classroom goal orientation in high school classroom: Revealing links between teacher beliefs and classroom environments. Educational Research, 46, 74-90. 
15. Dowson, M., \& McInerney, M. (2001). Psychological parameters of students' social and work avoidance goals: A qualitative investigation. Journal of Educational Psychology, 93(1), 35-42.

16. Dweck, C. S. (1986). Motivational processes affecting learning. American Psychologist, 41, 1040-1048.

17. Elliot, A. J., (1999). Approach and avoidance motivation goals. Educational Psychologist, 34(3), 169-189.

18. Elliot, A. J., \& Church, M. (1997). A hierarchical model of approach and avoidance achievementmotivation. Journal of Personality and Social Psychology, 72(1), 218-232.

19. Elliot, A. J., Murayama, K., \& Pekrun, R. (2011). A 3 X 2 achievement goal model. Journal of Educational Psychology, 103(3), 632-648.

20. Everson, H. T., Smodlaka, I., \& Tobias, S. (1994). Exploring the relationship of test anxiety and metacognition on reading test performance: A cognitive analysis. Anxiety, Stress, and Coping, 7, 85-96.

21. Flavell, J. H. (1979). Metacognition and cognitive monitoring: a new area of cognitive developmental inquiry. American Psychologist, 34, 906-911.

22. Heils, A. R., \& van Kraayenoord, C. E. (2003). Reading, metacognition and motivation: a follow-up study of German students in grades 7 and 8. European Journal of Psychology and Education, 1, 75-86.

23. Isaacson, R. M., \& Was, C. A. (2010). Believing You're Correct vs. Knowing You're Correct: A Significant difference? The Researcher, 23, 1-12.

24. Jan, J., \& Hall, R. (2005). The effects of social desirability bias on applied measures of goal orientation. Personality and Individual Differences, 38, 1891-1902.

25. Lan,W. Y. (1996). The effects of self-monitoring on students' course performance, use of learning strategies, attitude, self-judgment ability, and knowledge representation. The Journal of Experimental Education, 64, 101-115.

26. Meece, J., Anderman, E., \& Anderman, L. (2006). Classroom goal structure, student motivation, and academic performance. Annual Review of Psychology, 57(1), 487-503.

27. Middleton, M., Kaplan, A., \& Midgley, C. (1998). Achievement goal orientation and self-efficacy: Different goals, different relations. Paper presented at the annual meeting of the American Educational Research Association, San Diego, CA.

28. Middleton, M., \& Midgley, C. (1997). Avoiding the demonstration of lack of ability: An underexplored aspect of goal theory. Journal of educational psychology, 89, 710-718.

29. Midgley, C., Maehr, M., Hruda, L., Anderman, E., Anerman, L., Freeman, K., Urdan, T. (2000). Manual for the patterns of adaptive learning scales. Ann Arbor, MI: The University of Michigan.

30. Midgley, C., \& Urdan, T. (1995). Predictors of middle school students' use of self-handicapping strategies. Journal of Early Adolescence, 15, 389-411.

31. Moore, R. (2007). Academic motivation and performance of developmental education biology students. Journal of Developmental Education, 31(1), 24-34.

32. Nicholls, J. (1984). Achievement motivation: Conceptions of ability, subjective experience, task choice, and performance. Psychological Review, 91, 328-346.

33. Paulsen, M., \& Gentry, J. (1995). Motivation, learning strategies, and academic performance; a study of the college finance classroom. Financial Practice \& Education, 5(1), 78-89.

34. Pintrich, P. (2000). Multiple goals, multiple pathways: The role of goal orientation in learning and achievement. Journal of Educational Psychology, 92, 544-555.

35. Pintrich, P., \& DeGroot, E. (1990). Motivational and self-regulated learning components of classroom academic performance. Journal of Educational Psychology, 82, 33-40.

36. Roeser, R., Midgley, C., \& Urdan, T. (1996). Perceptions of the school psychological environment and early adolescents' psychological and behavioral functioning in school: The mediating role of goals and belonging. Journal of Educational Psychology, 88, 408-422.

37. Schunk, D. H. (1981). Modeling and attributional effects on children's achievement: A self-efficacy analysis. Journal of Educational Psychology, 73, 93-105.

38. Schunk, D. H. (1989). Self-efficacy and cognitive achievement: Implications for students with learning problems. Journal of Learning Disabilities, 22, 14-22.

39. Schunk, D. H. (1991). Self-efficacy and academic motivation. Educational Psychologist, 26, 207-231.

40. Skaalvik, E. M. (1997). Self-enhancing and self-defeating ego orientation: Relations with task and avoidance orientation, achievement, self-perceptions, and anxiety. Journal of Educational Psychology, 89, 71-81. 
41. Somuncuoglu, Y., \& Yildirim, A. (1999). Relationship between achievement goal orientations and use of learning strategies. The Journal of Educational Research, 92, 267-277.

42. Tobias, S., \& Everson, H. T. (1996). Assessing metacognitive knowledge monitoring. (College Board Report No. 96-01). NY: The College Board.

43. Tobias, S., \& Everson, H. T. (2002). Knowing what you know and what you don't: Further research on metacognitive knowledge monitoring (College Board Report. No. 2002-03). New York: College Board.

44. Tobias, S., \& Everson, H. T. (2009). The importance of knowing what you know: A knowledge monitoring framework for studying metacognition in education. In D. J. Hacker, J. Dunlosky, \& A. C. Graesser (Eds.), Handbook of metacognition in education (pp. 107-127). New York, NY: Routledge.

45. Tobias, S., Galvin, K., \& Michna, G. (2002, April). Motivation, metacognition, and help seeking. Paper presented at the annual convention of the American Educational Research Association convention, New Orleans, LA.

46. Tobias, S., Hartman, H., Everson, H., \& Gourgey, A. (1991, August). The development of a group administered, objectively scored metacognitive evaluation procedure. Paper presented at the annual convention of the American Psychological Association, San Francisco, CA.

47. Turner, C., Thorpe, P., \& Meyer, D. (1998). Students' report of motivation and negative affect: A theoretical and empirical analysis. Journal of Educational Psychology, 90(4), 758-771.

48. Urdan, T. C. (2001). Contextual influences on motivation and performance: An examination of achievement goal structure. In F. Salili, C. Chiu, \& Y. Hong (Eds.), Student motivation: The culture and context of learning (pp. 171-201). New York: Kluwer/Plenum.

49. Urdan, T., Kneisel, L., \& Mason, V. (1999). Interpreting messages about motivation in the classroom: Examining the effects of achievement goal structures. In T. Urdan (Eds.), The role of context (pp. 123-158). Stamford, CT: JAI.

50. Verkuyten, M., Thijs, J., \& Canatan, K. (2001). Achievement motivation and academic performance among Turkish early and young adolescents in the Netherlands. Genetic, Social, and General Psychology Monographs, 127(4), 378-408.

51. Vrugt, A., \& Oort, F. J. (2008). Metacognition, achievement goals, study strategies and academic achievement: Pathways to achievement. Metacognition and Learning, 30,123-146.

52. Was, C. (2006). Academic achievement goal orientation: Taking another look. Electronic Journal of Research in Educational Psychology, 4(3), 529-550.

53. Wolters, C. A., Yu, S. L., \& Pintrich, P. R. (1996). The relation between goals orientation and students' motivational beliefs and self-regulated learning. Learning and Individual Differences, 8, 211-238.

54. Yunus, A. S., \& Ali, W. Z. (2008). Metacognition and motivation in mathematical problem solving. The International Journal of Learning, 15, 121-131.

55. Zimmerman, B. J. (2000). Self-efficacy: An essential motive to learn. Contemporary Educational Psychology, 25, 82-91. 
NOTES 